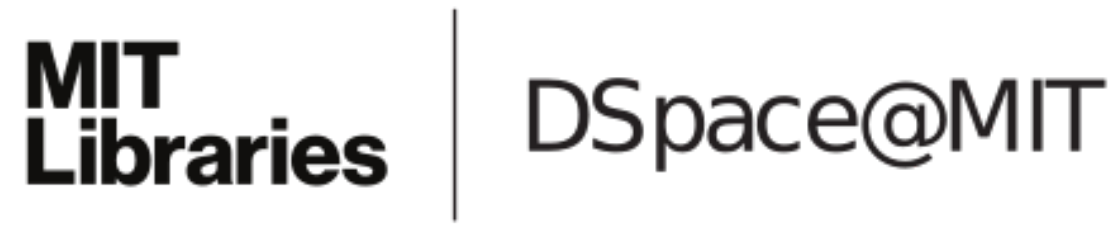

\author{
MIT Open Access Articles
}

\section{Low emissivity high-temperature tantalum thin film coatings for silicon devices}

The MIT Faculty has made this article openly available. Please share how this access benefits you. Your story matters.

Citation: Rinnerbauer, Veronika et al. “Low Emissivity High-temperature Tantalum Thin Film Coatings for Silicon Devices." Journal of Vacuum Science \& Technology A: Vacuum, Surfaces, and Films 31.1 (2013): 011501. (C) 2013 American Vacuum Society

As Published: http://dx.doi.org/10.1116/1.4766295

Publisher: American Vacuum Society (AVS)

Persistent URL: http://hdl.handle.net/1721.1/77144

Version: Final published version: final published article, as it appeared in a journal, conference proceedings, or other formally published context

Terms of Use: Article is made available in accordance with the publisher's policy and may be subject to US copyright law. Please refer to the publisher's site for terms of use. 


\title{
Low emissivity high-temperature tantalum thin film coatings for silicon devices
}

\author{
Veronika Rinnerbauer, ${ }^{\text {a) }}$ Jay J. Senkevich, John D. Joannopoulos, Marin Soljačić, \\ and Ivan Celanovic \\ Institute of Soldier Nanotechnologies, Massachusetts Institute of Technology, Cambridge, \\ Massachusetts 02139 \\ Robert R. Harl and Bridget R. Rogers \\ Department of Chemical and Biomolecular Engineering, Vanderbilt University, Nashville, Tennessee 37235
}

(Received 23 August 2012; accepted 18 October 2012; published 7 November 2012)

\begin{abstract}
The authors study the use of thin $(\sim 230 \mathrm{~nm})$ tantalum $(\mathrm{Ta})$ layers on silicon $(\mathrm{Si})$ as a low emissivity (high reflectivity) coating for high-temperature Si devices. Such coatings are critical to reduce parasitic radiation loss, which is one of the dominant loss mechanisms at high temperatures (above $700{ }^{\circ} \mathrm{C}$ ). The key factors to achieve such a coating are low emissivity in the near infrared and superior thermal stability at high operating temperatures. The authors investigated the emissivity of Ta coatings deposited on $\mathrm{Si}$ with respect to deposition parameters, and annealing conditions, and temperature. The authors found that after annealing at temperatures $\geq 900^{\circ} \mathrm{C}$ the emissivity in the near infrared $(1-3 \mu \mathrm{m})$ was reduced by a factor of 2 as compared to bare $\mathrm{Si}$. In addition, the authors measured thermal emission at temperatures from 700 to $1000^{\circ} \mathrm{C}$, which is stable up to a heater temperature equal to the annealing temperature. Furthermore, Auger electron spectroscopy profiles of the coatings before and after annealing were taken to evaluate thermal stability. A thin (about $70 \mathrm{~nm}$ ) $\mathrm{Ta}_{2} \mathrm{O}_{5}$ layer was found to act as an efficient diffusion barrier between the $\mathrm{Si}$ substrate and the Ta layer to prevent Si diffusion. (C) 2013 American Vacuum Society.

[http://dx.doi.org/10.1116/1.4766295]
\end{abstract}

\section{INTRODUCTION}

Silicon $(\mathrm{Si})$ is a very promising platform for hightemperature MEMS based energy conversion devices, including pyroelectric, thermoelectric thermal-to-electrical energy harvesting devices, and fuel cells. ${ }^{1-3}$ The key loss mechanisms in these systems are heat conduction and radiation; therefore, it is imperative to minimize heat losses on small device scales. Since radiative heat loss from a surface to the environment is increasing proportional to $T^{4}$ and $\mathrm{Si}$ has a high emissivity in the near infrared (IR) of about $0.7,{ }^{4}$ radiation is one of the dominant losses at high operating temperatures (above $700{ }^{\circ} \mathrm{C}$ ) in Si devices. ${ }^{5}$ However, there is a very limited body of work on high-temperature highly reflective coatings for Si devices. We have investigated a Si compatible, high-temperature, low emissivity (high reflectivity) coating to minimize radiation losses. The key challenges for such a coating are: thermomechanical stability regarding delamination, thermochemical stability regarding silicide formation and diffusion at high operating temperatures, achieving long term high-temperature stability, and high reflectivity. Metal coatings, in particular refractory metals, on $\mathrm{Si}$ are of interest to achieve low emissivity and reduce parasitic radiation loss in high-temperature devices. While other properties like resistivity, crystallinity, diffusion, and mechanical properties for metal coatings on Si have been investigated, ${ }^{6-8}$ mainly for microelectronic applications, there is little literature on the optical properties of such coatings, in particular at high temperatures, and their temperature stability.

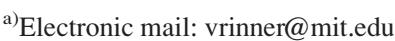

To achieve high-temperature stable low emissivity surfaces, we have chosen a multilayer platform based on a $\mathrm{Si}$ substrate, an optional adhesive coating, a diffusion barrier, and a low emissivity material capping material. We have investigated tantalum (Ta) as the low emissivity layer since it has a high melting point and low vapor pressure in addition to its low emissivity in the near IR $(\leq 0.1$ above $\sim 1 \mu \mathrm{m}$ ). We have characterized the optical properties as a function of the deposition parameters, the annealing conditions, as well as their surface roughness and sheet resistance. We have experimentally demonstrated that the emissivity can be decreased after deposition by annealing at high temperatures (above $900^{\circ} \mathrm{C}$ ), which is attributed to a densification process of the deposited Ta layers. In addition to room temperature (RT) emissivity, we have characterized hightemperature emission of these layers. Indeed, the emissivity is stable up to temperatures corresponding approximately to the annealing temperature. We have also investigated the role of a thin diffusion barrier layer of tantalum oxide $\left(\mathrm{Ta}_{2} \mathrm{O}_{5}\right)$ on silicide formation and thermal stability, and found that it strongly inhibits $\mathrm{Si}$ diffusion from the substrate into the Ta layer under high-temperature treatment.

\section{EXPERIMENT}

Samples of Ta layers on $\mathrm{Si}$ were prepared by electron beam (e-beam) evaporation. The substrate was $\mathrm{Si}$, and on half of the samples a $70 \mathrm{~nm}$ thick layer of $\mathrm{Ta}_{2} \mathrm{O}_{5}$ was deposited by e-beam evaporation at a base pressure of about $5 \times 10^{-6}$ Torr, with a deposition rate of $1 \AA$ \&s. Subsequently, a layer of $230 \mathrm{~nm}$ Ta was deposited on both bare Si wafers 
and $\mathrm{Si} / \mathrm{Ta}_{2} \mathrm{O}_{5}$ wafers at two different conditions: at a rate of $1 \AA / \mathrm{s}$ and a base pressure of $7 \times 10^{-7}$ Torr (referred to as slow) and at a rate of $2 \AA / \mathrm{s}$ at $7 \times 10^{-6}$ Torr (referred to as fast). We found that the mechanical stability of these layers was sufficient and there was no need for an adhesion coating.

Prepared samples were annealed in a tube furnace under forming gas $(95 \% \mathrm{~N}, 5 \% \mathrm{H})$ atmosphere (at 0.1 Torr) to increase high-temperature stability. The base pressure before flowing the forming gas was $<4 \times 10^{-6}$ Torr. The anneal time was $60 \mathrm{~min}$ at 900,950 , and $1000^{\circ} \mathrm{C}$, respectively, with a slow heating and cool down ramp of $10^{\circ} \mathrm{C} / \mathrm{min}$.

We experimentally obtain emissivity, the key optical parameter, at room temperature both before and after annealing from reflectance measurements in the IR $(1-3 \mu \mathrm{m})$ and from spectroscopic ellipsometry measurements in the visible and near IR $(0.19-1 \mu \mathrm{m})$. As the prepared samples are opaque and there is no transmission in the investigated wavelength range, the emissivity $E$ and reflectivity $R$ amount to unity according to Kirchhoff's law: $E=1-R$. In addition to room temperature measurements, a Nexus 870 Fourier transform infrared spectrometer (FTIR) was used to measure emission (at normal angle) from samples heated in a vacuum chamber under forming gas atmosphere, with heater temperatures ranging from 700 to $1000^{\circ} \mathrm{C}$. To retrieve information on the oxygen content and element distribution of the deposited layers, samples before annealing and after annealing at $950{ }^{\circ} \mathrm{C}$ were examined via Auger electron spectroscopy (AES) measurements.

\section{RESULTS AND DISCUSSION}

\section{A. Emissivity and annealing}

The spectral emissivity for the as-deposited samples at room temperature was found to be much lower in the near IR than for $\mathrm{Si}$ (at high temperatures) but higher than expected for $\mathrm{Ta}^{9}$ or tantalum silicide $\left(\mathrm{TaSi}_{2}\right)^{10-12}$ as taken from literature (see Fig. 1). The emissivity in the measured range was found to depend first on the deposition parameters, and second on the annealing conditions, as discussed

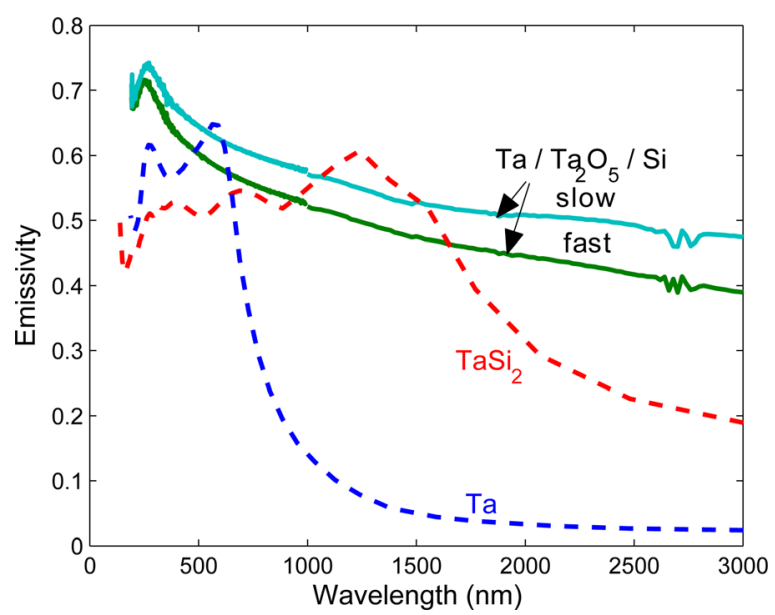

FIG. 1. (Color online) Emissivity of $\mathrm{Ta}^{9}$ and $\mathrm{TaSi}_{2}{ }^{10}$ (dashed lines) as compared to measured emissivity at room temperature of as-deposited $\mathrm{Ta} / \mathrm{Ta}_{2} \mathrm{O}_{5} / \mathrm{Si}$ samples (solid lines), deposited at a rate of $2 \AA / s$ (fast) and at a rate of $1 \AA / s$ (slow). below. The difference in emissivity between the deposited Ta layers and pure Ta, as shown in Fig. 1, is attributed to the porosity and grain structure of the layers as a result of the deposition process and contamination of the layers with carbon and oxygen as found by AES. A striking difference in the near IR emissivity was found for layers deposited at different rates, the lower deposition rate of $1 \AA / \mathrm{s}$ leading to an emissivity that is up to 0.08 higher as compared to layers deposited at the higher deposition rate of $2 \AA / s$ (see Fig. 1). This difference in emissivity is attributed to different material density (porosity and grain sizes) in those layers, caused by deposition. It was observed that the emissivity of samples with or without Ta oxide below the Ta layer was quite similar. The penetration depth of light $\delta$ is about $13-16 \mathrm{~nm}$ in the IR for Ta, defined as the distance over which the intensity of light in a material drops to $1 / \mathrm{e}$ of the initial value and given by $\delta=1 / \alpha=\lambda_{0} /(4 \pi k)$, where $\alpha$ is the absorption coefficient and $k$ is the imaginary part of the refractive index. The thickness of the Ta layer by far exceeds the penetration depth, and therefore $\mathrm{Ta}$ is the emissive layer and those samples are equivalent regarding room temperature emissivity.

After annealing samples at temperatures from 900 to $1000^{\circ} \mathrm{C}$ for an hour, the emissivity measured at RT decreased in all samples. The effect was strongest after annealing at
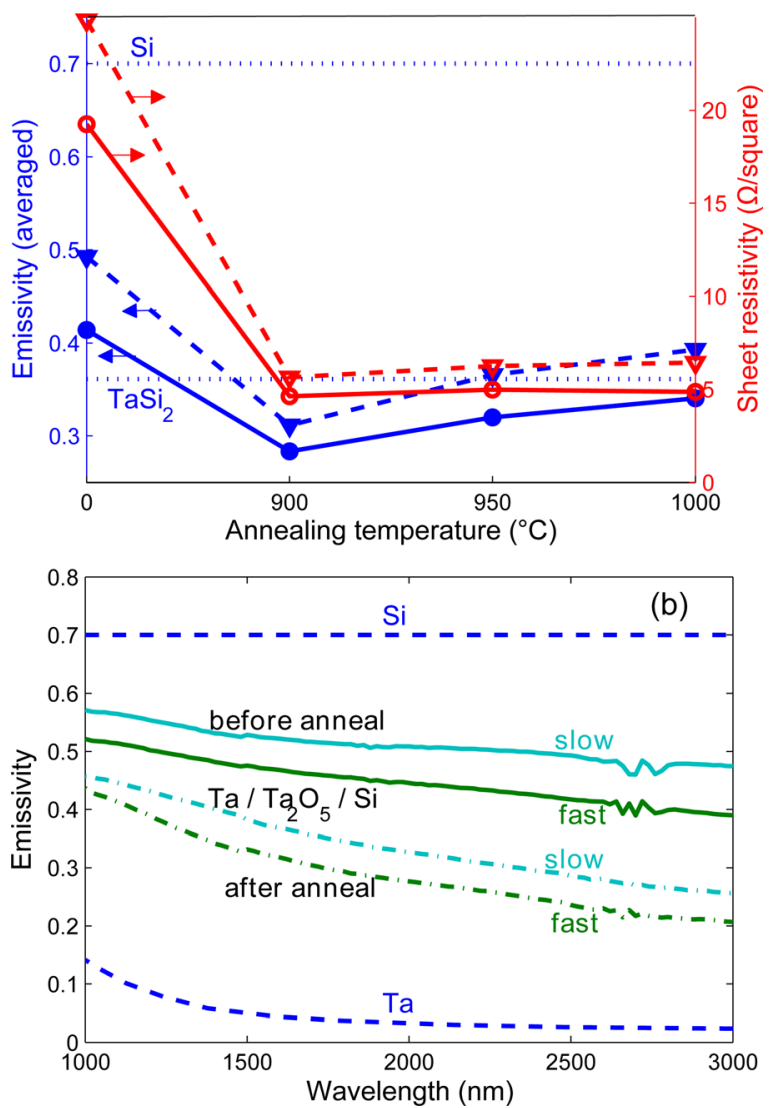

FIG. 2. (Color online) (a) Emissivity averaged over $1-3 \mu \mathrm{m}$ (blue) and sheet resistance (red) before and after annealing at different temperatures for $\mathrm{Ta} / \mathrm{Si}$ samples deposited at slow rate (triangles) and fast rate (circles) (lines are a guide to the eyes), and averaged emissivity of $\mathrm{TaSi}_{2}$ and $\mathrm{Si}$ (dotted lines). (b) Emissivity spectra before annealing (solid lines) and after annealing at $900^{\circ} \mathrm{C}$ (dashed-dotted lines), compared to emissivity of Ta and Si taken from literature (dashed lines). 
$900^{\circ} \mathrm{C}$ whereas the decrease in emissivity was weaker for higher annealing temperatures, as shown in Fig. 2. The emissivity (averaged over $1-3 \mu \mathrm{m}$ ) was 0.28 and 0.31 for fast and slow $\mathrm{Ta} / \mathrm{Si}$ samples after annealing at $900^{\circ} \mathrm{C}$, respectively, 0.31 and 0.37 after annealing at $950{ }^{\circ} \mathrm{C}$, and 0.34 and 0.39 after annealing at $1000^{\circ} \mathrm{C}$ for an hour, as compared to 0.41 (fast) and 0.49 (slow) as deposited before annealing. The averaged emissivity in the near IR after annealing was smaller by about a factor of 2 than that of bare $\mathrm{Si}$ (with an emissivity of 0.7 above $650{ }^{\circ} \mathrm{C}^{4}$ ) and below that of $\mathrm{TaSi}_{2}$ (average emissivity 0.37 over $1-3 \mu \mathrm{m}$ as calculated from Ref. 12), as depicted in Fig. 2. During annealing at high temperatures, there are at least two processes taking place in parallel: first, a change in morphology, grain structure and porosity and second, an increase in surface roughness. Those two processes result in different effects on the optical properties of the sample, as discussed below.

To study the role of the morphology change, we investigated the sheet resistance of the samples before and after annealing. The decrease in the emissivity after annealing is strongly correlated to the sheet resistance of the samples, as measured by a 4-point probe. After annealing, the sheet resistance decreased to about one fourth of the original value (see Fig. 2) which indicates increased density of the layer, a decrease in porosity and a growth of grains. ${ }^{13}$ The decrease in emissivity after annealing can be attributed to this densification with annealing at high temperatures. Following the effective medium theory, ${ }^{14,15}$ the effective refractive index of a heterogenous medium is depending on the volume fraction of the two constituents, and limited by the Wiener bounds. As the fraction of air respective voids and grain boundaries to metal decreases with annealing in our samples, the effective refractive index increases, leading to higher reflectivity.

To investigate the correlation of emissivity and surface roughness before and after annealing, atomic force microscopy (AFM) scans of the sample surface were taken and the surface roughness $R_{a}$ determined (see Fig. 3). The surface roughness increased only slightly from $R_{a}=0.25 \mathrm{~nm}$ before to $R_{a}=0.64 \mathrm{~nm}$ after annealing at $900{ }^{\circ} \mathrm{C}$, but significantly more during annealing at $950^{\circ} \mathrm{C}\left(R_{a}=2.9 \mathrm{~nm}\right)$ and $1000^{\circ} \mathrm{C}$ $\left(R_{a}=4.7 \mathrm{~nm}\right)$. As the roughened surface leads to more scattering and the increased air/metal fraction leads to a decrease
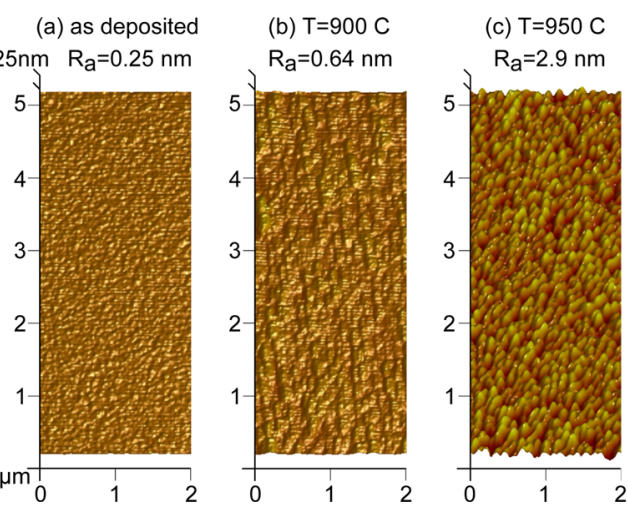

(d) $T=1000 \mathrm{C}$

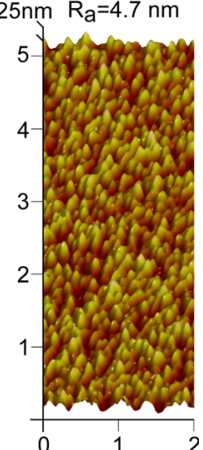

FIG. 3. (Color online) AFM images and surface roughness $R_{a}$ of $\mathrm{Ta} / \mathrm{Si}$ (fast rate): (a) as deposited before annealing, and after annealing for $1 \mathrm{~h}$ at (b) $900^{\circ} \mathrm{C}$, (c) $950^{\circ} \mathrm{C}$, and (d) $1000^{\circ} \mathrm{C}$. in the refractive index, the reflectivity was decreased and hence, emissivity was increased in samples annealed at higher temperatures as compared to annealing at $900^{\circ} \mathrm{C}$. The effect of the surface roughness on the sheet resistance is negligible, as the surface roughness is small compared to the layer thickness (of about $230 \mathrm{~nm}$ ).

In addition to the characterization of room temperature emissivity, emission measurements were performed at high temperature, at heater temperatures ranging from 700 to $1000^{\circ} \mathrm{C}$, under forming gas atmosphere with the FTIR in a range from 1 to $8 \mu \mathrm{m}$. Figure 4 shows the measured emission spectra at different heater temperatures. Following Planck's law of thermal radiation, the emission increases with temperature and the emission maximum shifts to shorter wavelengths at higher temperatures.

Regarding thermal stability, the measured emission showed approximately the same behavior for all samples: The sample emission was stable, i.e., constant at constant heater temperature, up to a heater temperature (which is in general higher than the temperature of the sample surface in our setup) equal to the annealing temperature (see Fig. 4). At this heater temperature, the emissivity of the samples started changing slowly over time, and emission was increasing at long wavelengths. When cooling down, the emission at lower temperature was shifted slightly to longer wavelengths as compared to the original emission at the same temperature. This implicates that the emissivity of the sample was irreversibly increased at long wavelengths $(\geq 2.5 \mu \mathrm{m})$ due to the high-temperature treatment, which is attributed to increased surface roughness. The temperature limit on the thermal stability of the optical properties is therefore approximately given by the annealing temperature of the tantalum layers.

Care must be taken not to change the temperature of the samples too rapidly $\left(\leq 30^{\circ} \mathrm{C} / \mathrm{min}\right.$ in the emission measurements), since an abrupt change in temperature may lead to precipitates, probably induced by thermal stress. XPS measurements on a sample without $\mathrm{Ta}_{2} \mathrm{O}_{5}$ layer, that showed precipitations on the surface after a fast cool down, have shown

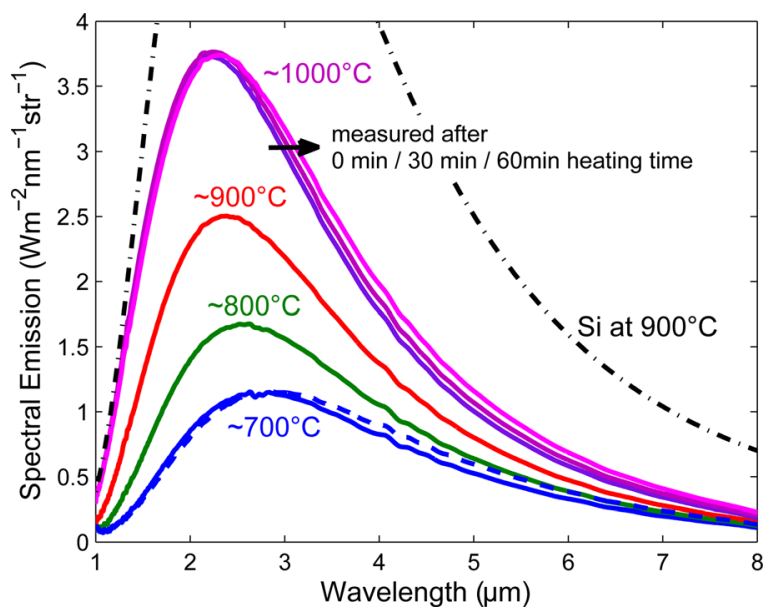

FIG. 4. (Color online) Emission spectra at different heater temperature for the $\mathrm{Ta} / \mathrm{Si}$ sample (fast rate) annealed at $1000^{\circ} \mathrm{C}$. The dashed blue line is the emission of $\mathrm{Ta} / \mathrm{Si}$ at a heater temperature of $700^{\circ} \mathrm{C}$ after heating up to $1000^{\circ} \mathrm{C}$ for $1 \mathrm{~h}$. For comparison: calculated emission of $\mathrm{Si}$ at a sample temperature of $900^{\circ} \mathrm{C}$ (black, dashed-dotted). 
these precipitates to be $\mathrm{Si}$ and carbon rich. AES profiles of the deposited layers confirmed the presence of $\mathrm{C}$ (for all samples) and $\mathrm{Si}$ (for samples without $\mathrm{Ta}_{2} \mathrm{O}_{5}$ layer) in the deposited layers, and their segregation toward the sample surface during high-temperature treatment.

\section{B. AES studies and silicide formation}

Previous studies have found substantial silicon diffusion and silicide $\left(\mathrm{TaSi}_{x}\right)$ formation at the interface of tantalum and silicon layers when exposed to elevated temperatures, starting at temperatures as low as $600^{\circ} \mathrm{C}^{8,16-18}$ In Ref. 18 , both the silicide formation as well as strong oxidation of $\mathrm{Ta}$ were observed when deposited on $\mathrm{SiO}_{2}$ and annealed above $1000{ }^{\circ} \mathrm{C}$. A reduction of $\mathrm{SiO}_{2}$ and formation of tantalum oxide $\mathrm{TaO}_{y}$ and tantalum silicide $\mathrm{TaSi}_{x}$ were observed even during sputter deposition of $\mathrm{Ta}$ on $\mathrm{SiO}_{2} / \mathrm{Si}$ substrates at lower substrate temperatures $\left(500^{\circ} \mathrm{C}\right) .{ }^{19}$ We anticipated a layer of $\mathrm{Ta}_{2} \mathrm{O}_{5}$ between $\mathrm{Ta}$ and $\mathrm{Si}$ to be an efficient barrier to silicide formation and thermal degradation in our approach, as $\mathrm{Ta}_{2} \mathrm{O}_{5}$ is readily formed and stable.
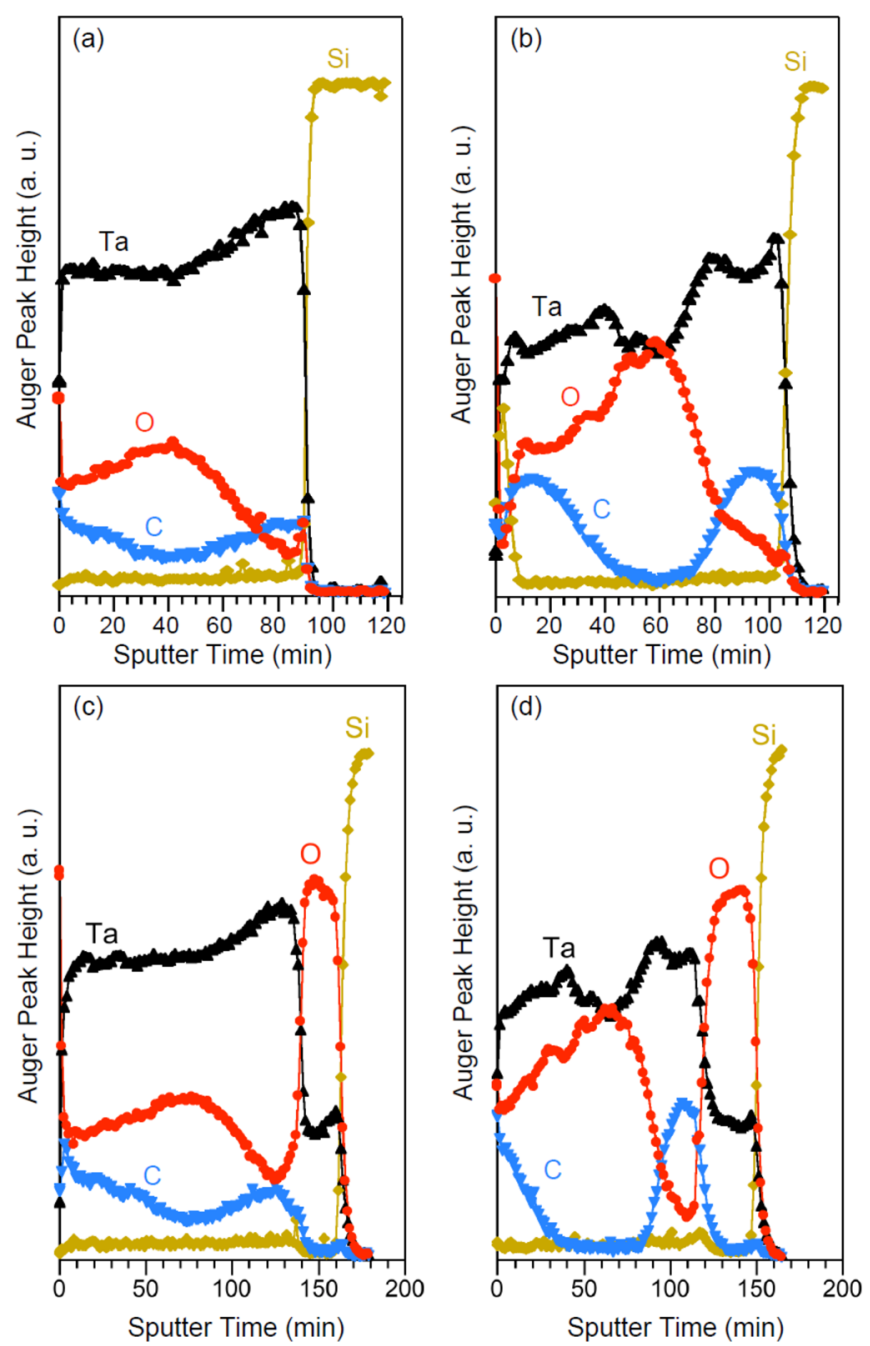

FIG. 5. (Color online) AES profiles of a $\mathrm{Ta} / \mathrm{Si}$ sample without $\mathrm{Ta}_{2} \mathrm{O}_{5}$ (slow rate) (a) before and (b) after annealing at $950^{\circ} \mathrm{C}$, and of a $\mathrm{Ta} / \mathrm{Ta}_{2} \mathrm{O}_{5} / \mathrm{Si}$ sample (slow rate) (c) before and (d) after annealing at $950^{\circ} \mathrm{C}$.
AES profiles of Ta layers both on $\mathrm{Si}$ and on $\mathrm{Ta}_{2} \mathrm{O}_{5} / \mathrm{Si}$ (Fig. 5) showed that there is a substantial amount of oxygen and carbon incorporation in the deposited Ta layers. This contamination originated from the deposition process, and hence can be minimized by better deposition procedures of the electron beam evaporation and use of higher purity deposition material. The source of carbon was thought to be the graphite crucible, which was probably gradually contaminating the deposition material through nonideal electron beam usage, and the oxygen was associated with oxidation of the deposition material between deposition runs. The Auger profiles also showed the migration of oxygen toward the center of the Ta layer during annealing, whereas the carbon was segregating toward the interfaces both in samples with and without $\mathrm{Ta}_{2} \mathrm{O}_{5}$ layer. In the samples without $\mathrm{Ta}_{2} \mathrm{O}_{5}$, a substantial amount of $\mathrm{Si}$ was found on the surface after annealing [Fig. 5(b)]. Si is migrating from the substrate to the surface via grain boundary diffusion at elevated temperatures, as found in previous studies. AES showed that in these samples, it was bound as silicon oxide rather than tantalum silicide; therefore, the impact on the emissivity is low. The oxygen contamination in the deposited Ta layers could actually have been increasing the thermal stability to some extend by suppressing formation of tantalum silicide in our layers, as compared to previous studies. Still, considering long term stability, Si diffusion is undesirable as it might lead to silicide formation eventually, increasing emissivity. In those samples with $\mathrm{Ta}_{2} \mathrm{O}_{5}$ between $\mathrm{Ta}$ and $\mathrm{Si}$, this silicon diffusion was substantially suppressed, and no $\mathrm{Si}$ was found on the Ta surface [Fig. 5(d)]. Therefore, a thin layer of $\mathrm{Ta}_{2} \mathrm{O}_{5}$ between the $\mathrm{Ta}$ and the $\mathrm{Si}$ substrate acts as an efficient high-temperature diffusion barrier layer.

\section{CONCLUSION}

Tantalum thin film $(\sim 230 \mathrm{~nm})$ layers on Si substantially decrease the emissivity (increase reflectivity) of $\mathrm{Si}$ in the near IR. The average emissivity in this range $(1-3 \mu \mathrm{m})$ after annealing (at temperatures from 900 to $1000^{\circ} \mathrm{C}$ ) decreased by a factor of 2 as compared to bare Si. In particular, emissivity was 0.28 and 0.31 for Ta layers deposited at 2 and $1 \AA$ /s, respectively, after annealing at $900^{\circ} \mathrm{C}$ compared to about 0.7 for Si. The emissivity of these Ta layers in the near IR depends in the first instance on the deposition parameters. We found that the emissivity in the near IR (above $1 \mu \mathrm{m})$ is higher than that of bulk Ta. This is due to the contamination of the Ta layers with $\mathrm{C}$ and $\mathrm{O}$ during e-beam evaporation deposition as shown by AES profiles, as well as the porosity of the deposited layers. In addition, we investigated dependence of the emissivity on the annealing temperature. The emissivity of all samples was decreased by annealing after deposition, which strongly correlated to the decrease in sheet resistance and was attributed to a change in morphology: a densification process, decreasing porosity, and grain growth at high-temperature treatment leading to both the decrease in sheet resistance and emissivity. We also found that higher annealing temperatures $\left(>900^{\circ} \mathrm{C}\right)$ lead to increased surface roughness, and a slight increase in 
measured emissivity as compared to lower annealing temperature $\left(900^{\circ} \mathrm{C}\right)$. Emission measurements at heater temperatures ranging from 700 to $1000{ }^{\circ} \mathrm{C}$ showed that the emission is stable up to a heater temperature comparable to the annealing temperature of the samples. AES profiles also showed that there is Si diffusion through the Ta layer toward the surface under high-temperature treatment, which is essentially suppressed by a thin $\mathrm{Ta}_{2} \mathrm{O}_{5}$ layer acting as a diffusion barrier between the Si substrate and the Ta layer.

These results suggest that thin Ta layers are a promising approach to a high-temperature, low emissivity coating on $\mathrm{Si}$ as well as potentially other substrates. An improved deposition process resulting in less contamination and higher density of the layers is anticipated to improve the presented emissivity results even further.

\section{ACKNOWLEDGMENTS}

The deposition of $\mathrm{Ta}$ and $\mathrm{Ta}_{2} \mathrm{O}_{5}$ layers was done at the Microsystems Technology Laboratory (MTL) of MIT. This work was partially supported by the Army Research Office through the Institute for Soldier Nanotechnologies under Contract Nos. DAAD-19-02-D0002 and W911NF-07-D000. M.S. was partially supported by the MIT S3TEC Energy Research Frontier Center of the Department of Energy under Grant No. DE-SC0001299. V.R. acknowledges funding by the Austrian Science Fund (FWF): J3161-N20.
${ }^{1}$ D. C. Walther and J. Ahn, Prog. Energy Combust. Sci. 37, 583 (2011).

${ }^{2}$ S. R. Hunter, N. V. Lavrik, S. Mostafa, S. Rajic, and P. G. Datskos, Proc. SPIE 8377, 83770D (2012).

${ }^{3}$ L. R. Arana, S. B. Schaevitz, A. J. Franz, M. A. Schmidt, and K. F. Jensen, J. Microelectromech. Syst. 12, 600 (2003).

${ }^{4}$ P. J. Timans, J. Appl. Phys. 74, 6353 (1993).

${ }^{5}$ L. R. Arana, "High-temperature microfluidic systems for thermally-efficient fuel processing," Ph.D. dissertation (Massachusetts Institute of Technology, 2003).

${ }^{6} \mathrm{M}$. Zier, S. Oswald, R. Reiche, and K. Wetzig, Anal. Bioanal. Chem. 375, 902 (2003).

${ }^{7}$ A. N. Mansour, Vaccum 85, 667 (2011).

${ }^{8}$ A. Z. Moshfegh and O. Akhavan, Mater. Sci. Semicond. Process. 6, 165 (2003).

${ }^{9}$ D. W. Lynch and W. R. Hunter, in Handbook of Optical Constants of Solids, edited by E. D. Palik (Elsevier, New York, 1998), p. 408.

${ }^{10}$ A. Borghesi, L. Nosenzo, A. Piaggi, G. Guizzeti, C. Nobili, and G. Ottaviani, Phys. Rev. B 38, 10937 (1988).

${ }^{11}$ M. Tanaka, S. Kurita, M. Fujisawa, and F. Levy, Phys. Rev. B 46, 10442 (1992).

${ }^{12}$ G. Guizetti and F. Marabelli, in Properties of Metal Silicides, edited by K. Maex and M. Van Rossum (Institution of Engineering and Technology, 1995), p. 240.

${ }^{13}$ A. W. Sood et al., J. Nanosci. Nanotechnol. 12, 3950 (2012).

${ }^{14}$ D. E. Aspnes, Am. J. Phys. 50, 704 (1982).

${ }^{15}$ O. Wiener, Abh. Math.-Phys. Kl. Säechs. Akad. Wiss. Leipzig 32, 509 (1912).

${ }^{16} \mathrm{C}$. Milanese, V. Buscaglia, F. Maglia, and U. Anselmi-Tambutini, J. Phys. Chem. B 106, 5859 (2002).

${ }^{17}$ K. Stella, D. Bürstel, E. Hasselbrink, and D. Diesing, Phys. Status Solidi 5, 68 (2011).

${ }^{18}$ R. Hübner, M. Hecker, N. Mattern, V. Hoffmann, K. Wetzig, H.-J. Engelmann, and E. Zschech, Anal. Bioanal. Chem. 379, 568 (2004).

${ }^{19}$ P. Gallais, J. J. Hantzpergue, J. C. Remy, and D. Roptin, Thin Solid Films 165, 227 (1988). 